\title{
Separation of emitted and photochemical formaldehyde in Mexico City using a statistical analysis and a new pair of gas-phase tracers
}

\author{
A. R. Garcia ${ }^{1, *}$, R. Volkamer ${ }^{1}$, L. T. Molina ${ }^{1}$, M. J. Molina ${ }^{1}$, J. Samuelson ${ }^{2}$, J. Mellqvist ${ }^{2}$, B. Galle ${ }^{2}$, S. C. Herndon ${ }^{3}$, \\ and C. E. Kolb ${ }^{3}$ \\ ${ }^{1}$ Dept. of Earth, Atmospheric and Planetary Sciences, Massachusetts Inst. of Technology, Cambridge, MA 01239-4307, USA \\ ${ }^{2}$ Chalmers Tekniska Hoegskola, Goeteborg, Sweden \\ ${ }^{3}$ Center for Atmospheric and Environmental Chemistry, Aerodyne Research, Inc. Billerica, MA 01821-3976, USA
}

Received: 2 August 2005 - Published in Atmos. Chem. Phys. Discuss.: 11 November 2005

Revised: 21 August 2006 - Accepted: 3 October 2006 - Published: 9 October 2006

\begin{abstract}
Photochemical pollution control strategies require an understanding of photochemical oxidation precursors, making it important to distinguish between primary and secondary sources of HCHO. Estimates for the relative strengths of primary and secondary sources of formaldehyde (HCHO) were obtained using a statistical regression analysis with time series data of carbon monoxide $(\mathrm{CO})$ and glyoxal (CHOCHO) measured in the Mexico City Metropolitan Area (MCMA) during the spring of 2003. Differences between Easter week and more typical weeks are evaluated. The use of CO-CHOCHO as HCHO tracers is more suitable for differentiating primary and secondary sources than $\mathrm{CO}-\mathrm{O}_{3}$. The application of the $\mathrm{CO}-\mathrm{O}_{3}$ tracer pair to mobile laboratory data suggests a potential in-city source of background HCHO. A significant amount of HCHO observed in the MCMA is associated with primary emissions.
\end{abstract}

\section{Introduction}

Improving the air quality in many large cities require a better understanding of the sources and transformation of pollutants in the atmosphere (see, e.g., Molina and Molina, 2002). Formaldehyde (HCHO) is the simplest and most abundant carbonyl in urban air. HCHO is carcinogenic (Vaughn et al., 1986), and highly water soluble (Dean, 1985), making respiration of air containing elevated levels of formaldehyde an efficient pathway for human exposure. Industrial emissions (Carlier et al., 1986) and mobile sources of directly emitted (primary HCHO) have been identified (Hoekman, 1992; Dodge, 1990; Carter, 1995; Anderson, 1996; Janning et al., 1996; Williams et al., 1990; Kean et al., 2001; Reyes et al., 2006) as sources for HCHO in the urban atmo-

Correspondence to: A. R. Garcia

(agustin@atmosfera.unam.mx) sphere. Realtime on-road measurements can quantify average fleet HCHO emissions (Kolb et al., 2004; Zavala et al., 2006) and quantify variable emissions among individual vehicles (Shorter et al., 2005). However, integrated estimates of primary $\mathrm{HCHO}$ from both the vehicle fleet and industrial sources are largely unavailable.

Formaldehyde can also be produced from the atmospheric oxidation of numerous VOCs (secondary HCHO) (Finlayson-Pitts and Pitts, 1986; Seinfeld, 1986; Altshuller, 1993; Dodge, 1990; Carter, 1995). Primary emission and secondary formation of formaldehyde both contribute to the ambient concentration of this compound. In urban air, ambient concentrations of HCHO typically range from 1-20 $\mathrm{ppb}_{v}$ (Carlier et al., 1986); lower concentrations are found in semi-urban and rural air masses inside the boundary layer (0.5 ppbv, Finlayson-Pitts and Pitts, 1986) and the background troposphere $(0.20 \mathrm{ppbv}$, Zhou et al., 1996). These variations are due to formaldehyde's relatively short daytime atmospheric life time (generally few hours), primarily determined by reaction with $\mathrm{OH}$-radicals and photolysis.

$\mathrm{HCHO}$ photolysis leads to the formation of $\mathrm{HO}_{2}$-radicals, which react with $\mathrm{NO}$ during the morning hours, rapidly converting to $\mathrm{OH}$-radicals. In the MCMA, HCHO photolysis is the dominant radical source sustaining photochemical smog formation in the late morning and throughout the day (Volkamer et al., 2005 $\left.\mathrm{a}^{1}\right)$. For control and regulatory purposes, it is important to differentiate between primary (directly emitted) and secondary (photochemically produced) sources of $\mathrm{HCHO}$, in order to identify those control policies that efficiently enable to reduce ambient $\mathrm{HCHO}$ concentrations and ultimately improve urban air pollution.

\footnotetext{
${ }^{1}$ Volkamer, R., Molina, L. T., Molina, M. J., et al.: Experimental quantification of the primary and secondary HOx formation in Mexico City, Atmos. Chem. Phys. Discuss., in preparation, 2005a.
}

Published by Copernicus GmbH on behalf of the European Geosciences Union. 
During the MCMA-2003 field campaign, held in April and early May 2003 in the Mexico City Metropolitan Area, measured $\mathrm{HCHO}$ concentrations ranged from 1 to $36 \mathrm{ppb}_{v}$ with a monthly average of $(8.2 \pm 4.6) \mathrm{ppb}_{v}$ at the Mexican National Center for Environmental Research and Training (CENICA) supersite (Volkamer et al., 2005b), in good agreement with the monthly average concentration of $(6.0 \pm 4.7) \mathrm{ppb}_{v}$ measured in downtown La Merced (Grutter et al., 2005).

It is not possible to distinguish between primary and secondary sources directly from ambient $\mathrm{HCHO}$ concentration measurements. Previous attempts to estimate their relative strengths have used a statistical analysis approach (Friedfeld et al., 2002) that aimed to reproduce the concentration-time series (ct-series) of ambient HCHO from a linear combination of ct-series of $\mathrm{CO}$ and $\mathrm{O}_{3}$ (or mathematical homologues) as tracers for primary and secondary $\mathrm{HCHO}$, respectively. In this paper, a similar approach is employed, using data from real-time open-path measurements conducted at the CENICA supersite during MCMA-2003. Besides the previous $\mathrm{CO}-\mathrm{O}_{3}$ tracer pair, a new tracer pair (CO-CHOCHO) is used as input for the statistical analysis, and the performance of both tracer pairs is compared. In both cases $\mathrm{CO}$ is an excellent indicator for primary $\mathrm{HCHO}$ (mobile sources contribute $99 \%$ of ambient CO; stationary point and area sources contribute only $1 \%$ in the MCMA - Secretaria del Medio Ambiente, 2002); the statistical weight of the HCHO to $\mathrm{CO}$ ratio is used to estimate the primary contribution to $\mathrm{HCHO}$ ambient concentrations. Secondary HCHO is correlated with a photochemical products, either $\mathrm{O}_{3}$ or glyoxal (CHOCHO). Unlike $\mathrm{O}_{3}, \mathrm{CHOCHO}$ does not react with nitric oxide (NO), and is essentially unaffected by traffic emissions. Its time-resolved direct detection in the atmosphere was demonstrated for the first time during MCMA2003, presenting a novel indicator molecule for VOC oxidation processes (Volkamer et al., 2005b). A further advantage of CHOCHO as indicator for secondary HCHO lies in the close analogy of their atmospheric sink reactions. Like $\mathrm{HCHO}, \mathrm{CHOCHO}$ is primarily removed by $\mathrm{OH}$-radical and photolysis loss processes (Atkinson, 2000) and daytime atmospheric residence times under typical MCMA conditions of both species are conditions comparable, i.e. about $2.2 \mathrm{~h}$ for CHOCHO (Volkamer et al., 2005b), and about twice as long for $\mathrm{HCHO}$

During MCMA-2003 two different emissions regimes were sampled: (1) before and after Easter week and (2) during Easter week, when emissions across the MCMA were considerably lower. The objective of this paper is to assess the relative contributions of primary and secondary $\mathrm{HCHO}$ to ambient $\mathrm{HCHO}$ concentrations at the CENICA supersite, and to assess the spatial variability of $\mathrm{HCHO}$ background concentrations by utilizing mobile laboratory measurements (Kolb et al., 2004) made throughout the MCMA.

\section{Method}

\subsection{CENICA central site}

The CENICA site is located approximately $10 \mathrm{~km}$ southeast of downtown Mexico City in the Iztapalapa campus of the Metropolitan Autonomous University (UAM). The area features commercial, residential and industrial buildings as well as the conservation area, Cerro de la Estrella.

During the MCMA-2003 campaign, the temperature at CENICA ranged from $10^{\circ} \mathrm{C}$ to $32^{\circ} \mathrm{C}$ and the relative humidity from $5 \%$ to $98 \%$. The measurement period was characterized by clear to partially clouded skies during the morning and afternoon hours, with some evenings featuring mild convective rainfalls.

\subsection{CENICA measurements}

Differential Optical Absorption Spectroscopy (DOAS) and Fourier Transform Infrared (FTIR) open path systems were deployed at CENICA. These instruments measured continuously gas phase pollutants as aromatics, ozone, carbon monoxide, carbon dioxide, formaldehyde, acetaldehyde and glyoxal, among others. The time series data include days from 4 April to 5 May 2003.

The FTIR system consisted of a medium resolution $\left(1 \mathrm{~cm}^{-1}\right)$ spectrometer (Bomem MB104) coupled to a custom fabricated transmitting and receiving telescope. At the other side of the light path, a cubecorner array was mounted at a tower, making up a total folded path of $860 \mathrm{~m}$. The system provided data with 5-min integration time. Spectra were analyzed using the latest HITRAN database cross sections (Rothman et al., 2000) and a nonlinear fitting algorithm.

The DOAS technique has been described elsewhere (Platt, 1994). The long-path DOAS (LP-DOAS) measured HCHO, $\mathrm{O}_{3}$, CHOCHO and other species by detection of their unique specific narrow-band $(<5 \mathrm{~nm})$ absorption structures in the ultraviolet and visible spectral ranges. The LP-DOAS was installed on the rooftop of the CENICA building, where light of a broadband UV/vis lightsource (Xe-short arc lamp) was projected into the open atmosphere towards an array of retro reflectors located in south-westerly direction on top of the local hill Cerro de la Estrella, folding the lightbeam back into the instrument, where spectra were recorded using a CzernyTurner type spectrometer coupled to a 1024-element PDA detector. The average height of the light path was $70 \mathrm{~m}$ above ground and a total path length was $4.42 \mathrm{~km}$. The experimental setup, evaluation algorithms and data are described in detail elsewhere (Volkamer et al., 2005b).

\subsection{Mobile laboratory measurements}

The mobile laboratory was deployed to three additional fixed sites in the MCMA. The highly urban Merced site is close to the center of the city. The residential Pedregal site, located to the southeast of the city center, typically receives 
middle and late afternoon aged emissions from the city. The rural Santa Ana site is located just outside the MCMA to the south and is more representative of the background conditions. The instrumentation aboard the mobile laboratory and methods used for its analysis have been described elsewhere (Canagaratna et al., 2004; Kolb et al., 2004; and Herndon et al., 2005b). Formaldehyde was measured using tunable infrared differential absorption spectroscopy (TILDAS). During the MCMA 2003 campaign, a pair of absorptions lines at 1774.67 and $1774.83 \mathrm{~cm}^{-1}$ were used to determine HCHO concentrations (Herndon et al., 2005). Two relatively weak water lines bracket these features, and a very small water line is present in the gap between. There are no other known strongly absorbing species found in an urban setting in this region. As operated during these measurements, the $1 \mathrm{~s} \mathrm{rms}$ precisions for $\mathrm{HCHO}$ was normally less than $1.1 \mathrm{ppb}$. CO and $\mathrm{O}_{3}$ were measured using conventional commercial infrared and ultraviolet absorption instruments, respectively. Due to a problem discovered in the $\mathrm{O}_{3}$ monitor deployed aboard the mobile laboratory, a correction has been applied to the mobile data (Dunlea et al., 2005). When other fixed site data was available for $\mathrm{O}_{3}$, it was used. As part of the quality assurance of ambient $\mathrm{HCHO}$ measurements, adjustments to the absorption cross-section of HCHO in the UV and IR- spectral ranges were performed to assure matching calibration of HCHO measurements by DOAS and TILDAS as discussed in (Volkamer et al., 2005c $\mathrm{c}^{2}$ ).

\subsection{Statistical analyses}

All statistical analyses were performed using Intercooled STATA $8^{\circledR}$. Linear regressions models were applied to the time series data set for $\mathrm{HCHO}, \mathrm{CO}, \mathrm{O}_{3}$ and $\mathrm{CHOCHO}$. In order to identify the most suitable model for the time series data, two evaluations were performed. The first used $\mathrm{HCHO}, \mathrm{CO}$ and $\mathrm{O}_{3}$ series applying ten different transformations: linear (no transformation), natural log, square root, second power, 3rd power, inverse, inverse of natural log, inverse of square root, inverse of second power and inverse of 3rd power. The second approach used the same transformations with $\mathrm{HCHO}, \mathrm{CO}$ and $\mathrm{CHOCHO}$.

The special case of a linear model was with the second approach, is represented by the equation:

$$
[\mathrm{HCHO}]=\beta_{0}+\beta_{1}[\mathrm{CHOCHO}]+\beta_{2}[\mathrm{CO}]
$$

For every unit increase in $\mathrm{CHOCHO}$ concentration there is a $\beta_{1}$ unit increase in $\mathrm{HCHO}$; for every unit increase in $\mathrm{CO}$ concentration there is a $\beta_{2}$ unit increase in $\mathrm{HCHO} ; \beta_{0}$ represents

\footnotetext{
${ }^{2}$ Volkamer, R., Zavala, M., Molina, L. T., Molina, M. J., Samuelsson, J., Mellqvist, J., Galle, B., Herndon, S., Kolb, C., Knighton, B., Flores, E., and Grutter, M.: Open-path emission factors derived from DOAS and FTIR Measurements in the Mexico City Metropolitan Area, Atmos. Chem. Phys. Discuss., in preparation, 2005c.
}

residual $\mathrm{HCHO}$, which is associated with either primary nor secondary $\mathrm{HCHO}$, and is referred henceforth as background $\mathrm{HCHO}$ (in units of $\mathrm{ppb}_{v}$ ). Background $\mathrm{HCHO}$ may be due to alternative $\mathrm{HCHO}$ sources not represented by the indicator surrogates for primary and secondary $\mathrm{HCHO}$, or due to a different lifetime of $\mathrm{HCHO}$ and these surrogates, which may introduce a bias in the $\beta$-values of Eq. (1).

To estimate the contribution of $\mathrm{CO}$ and $\mathrm{CHOCHO}$ to primary and secondary $\mathrm{HCHO}$ to the ambient concentration to $\mathrm{HCHO}$, it is necessary to scale the values of $\mathrm{CO}$ and CHOCHO by their respective $\beta$ value.

Contributions due to the photochemistry, emissions and background $\mathrm{HCHO}$ can be computed with the following equations:

$$
\begin{aligned}
& \% \text { pho }=\frac{\sum\left(\beta_{1}[\mathrm{CHOCHO}]_{i}\right)}{\sum\left(\beta_{1}[\mathrm{CHOCHO}]_{i}+\beta_{2}[\mathrm{CO}]_{i}+\beta_{0}\right)} \times 100 \\
& \% \text { emiss }=\frac{\sum \beta_{2}[\mathrm{CO}]_{i}}{\sum\left(\beta_{1}[\mathrm{CHOCHO}]_{i}+\beta_{2}[\mathrm{CO}]_{i}+\beta_{0}\right)} \times 100 \\
& \% \text { bkgr }=\frac{\beta_{0}}{\sum\left(\beta_{1}[\mathrm{CHOCHO}]_{i}+\beta_{2}[\mathrm{CO}]_{i}+\beta_{0}\right)} \times 100
\end{aligned}
$$

Where \%pho represents the contribution of secondary HCHO (photochemical VOC oxidation) and \%emiss is the contribution from primary sources (vehicle emissions); $\%$ bkgr indicates $\mathrm{HCHO}$, which can neither be accounted as primary or secondary $\mathrm{HCHO}$. $[\mathrm{CHOCHO}]_{i}$ and $[\mathrm{CO}]_{i}$ represent the concentrations of $\mathrm{CHOCHO}$ and $\mathrm{CO}$ respectively at time $\mathrm{i}$ and $\beta_{0}, \beta_{1}$ and $\beta_{2}$ are the coefficients obtained by the linear regression (see Eq. 1).

As part of the sensitivity tests, the effect of remaining differences in atmospheric lifetime of $\mathrm{CHOCHO}$ and $\mathrm{HCHO}$ on the results of the statistical analysis was investigated using alternative concentration time profiles for $\mathrm{CHOCHO}$ and $\mathrm{HCHO}$ concentrations, which were corrected for losses due to photolysis loss and $\mathrm{OH}$ reaction and were derived as follows:

$$
[\mathrm{X}]_{\text {corr }}=[\mathrm{X}]\left(1+J_{x} \Delta t+K_{\mathrm{OH}-\mathrm{X}}[\mathrm{OH}] \Delta t\right)
$$

Where X represents either $\mathrm{HCHO}$ or $\mathrm{CHOCHO}, J_{x}$ is the photolysis frequency for $\mathrm{X}$ as measured by spectroradiometry (Volkamer et al., 2005b), $K_{\mathrm{OH}-\mathrm{X}}$ is the reaction rate between $\mathrm{OH}$ and $\mathrm{X}$ (Sander et al., 2002), $[\mathrm{OH}]$ the measured concentration of $\mathrm{OH}$-radicals (Shirley et al., 2005), and $\Delta t$, the chosen time interval for correction, was (varied between $1-120 \mathrm{~min})$.

Further sensitivity tests aimed to correct the $\mathrm{CO}$ concentration time profile for influence due to the vertical mixing of air masses, which are likely depleted in their $\mathrm{HCHO} / \mathrm{CO}$ ratio. An extreme case was estimated assuming the $\mathrm{HCHO} / \mathrm{CO}$ ratio to be zero outside the planetary boundary layer, and corrections were calculated as follows:

$$
[\mathrm{CO}]_{\text {corr }}=[\mathrm{CO}]_{\text {measured }}-[\mathrm{CO}]_{\text {back }} \frac{(D-1)}{D}
$$




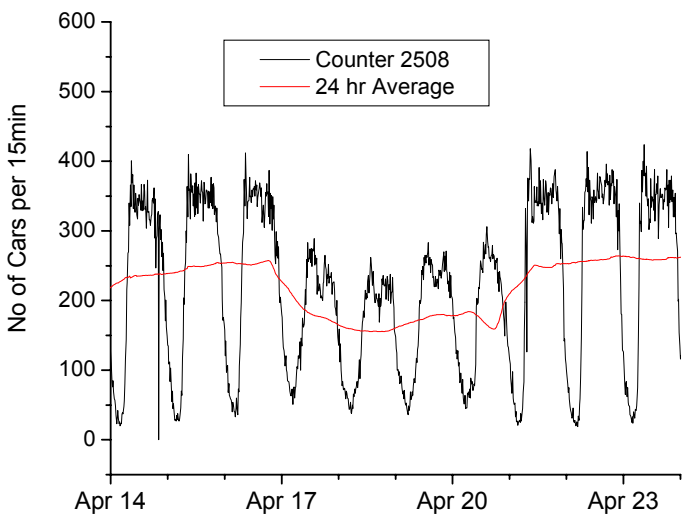

Fig. 1. Traffic count over Insurgentes Ave. $8 \mathrm{~km}$ towards west from CENICA during the 2003 April campaign.

Where $[\mathrm{CO}]_{\text {measured }}$ is the $\mathrm{CO}$ concentration from the ground measurements, $[\mathrm{CO}]_{\text {back }}$ is the $\mathrm{CO}$ concentration aloft the mixing height (taken as $60 \mathrm{ppbv}$, the value measured in the background sites outside the MCMA). $D$ is the dilution factor, which was calculated using $\mathrm{CO}$ as a chemically inert tracer for the variability of mixing height as follows:

$D=\frac{[\mathrm{CO}]_{\text {traffic }}}{[\mathrm{CO}]_{\text {measured }}}$

Where $D$ represents a relative factor by which the mixing height increased relative to the morning hours. $(D-1)$ thus represents the volume of air that contained $[\mathrm{CO}]_{\text {back }}$. $[\mathrm{CO}]_{\text {traffic }}$ is the estimated $\mathrm{CO}$ concentration under the mixing height due to vehicular emissions related to the traffic activity.

\section{Results and discussion}

Emissions activities varied over the field campaign; from Thursday to Sunday during the Easter week magnetic traffic counters at Insurgentes avenue measured 38\% fewer cars (see acknowledgment) than during same days in prior and subsequent weeks. Figure 1 shows the traffic variation during 10 days spanning the Easter holidays; the activity decrease during four-day period is noticeable. Reductions in the average concentrations of $\mathrm{CO}, \mathrm{O}_{3}, \mathrm{CHOCHO}$ and $\mathrm{HCHO}$ were observed; between Easter week, and the averages from the prior and subsequent weeks: accounting to $36 \%, 21 \%$, $44 \%$ and $36 \%$, respectively (on a $24 \mathrm{~h}$ average basis). Averages from 18 to 20 April were compared with averages from 15 to 16 and 21, 22 April. It is interesting to note that reductions in traffic have different effects in the concentrations of the different pollutants. While $\mathrm{CO}, \mathrm{CHOCHO}$ and $\mathrm{HCHO}$ more or less reflect the reduction in traffic on Insurgentes, the reduction in $\mathrm{O}_{3}$ is much less pronounced, though significant. The ct-series of $\mathrm{O}_{3}, \mathrm{CO}, \mathrm{HCHO}$ and $\mathrm{CHOCHO}$ mixing ratios, which are the basis for the statistical analysis, are shown in Fig. 2a. Easter week was from 18 to 20 April.
Figure $2 \mathrm{~b}$ presents an expansion of $\mathrm{O}_{3}, \mathrm{HCHO}$ and $\mathrm{CO}$ concentrations (approach 1) at CENICA, shown for a two day period shortly after Easter week. Similarly, in Figure 2c concentrations of $\mathrm{CHOCHO}, \mathrm{HCHO}$ and $\mathrm{CO}$ (approach 2) are shown for the same time interval. Open path data smooth out possible influence from any local sources near the sampling site. Figure 2 presents plots of $\mathrm{O}_{3}, \mathrm{HCHO}, \mathrm{CHOCHO}$ and $\mathrm{CO}$ concentrations at CENICA during mid and late April. The $\mathrm{CO}$ generally has lower concentrations during the Easter holidays (18-20 April).

Amplification of the time series in Figs. $2 b$ and $c$ show how $\mathrm{CO}$ and $\mathrm{HCHO}$ concentrations start to build up before sunrise, i.e. during the early morning rush hour. When the sun rises photochemical VOC transformations generate both $\mathrm{CHOCHO}, \mathrm{HCHO}$ and also lead to the production of $\mathrm{O}_{3}$. However, initial $\mathrm{O}_{3}$ production is suppressed due to the efficient titration reaction of $\mathrm{O}_{3}+\mathrm{NO}$, producing $\mathrm{NO}_{2}$. This process delays peak ozone to near noon. Furthermore, efficient $\mathrm{O}_{3}$ production in the MCMA compensates its dilution in the rising boundary layer. The result is accumulating amounts of $\mathrm{O}_{3}$ in the later morning, which is typical for $\mathrm{O}_{3}$, but is not observed for the other species. In comparing panel $\mathrm{b}$ and $\mathrm{c}$, the better match of the $\mathrm{CHOCHO}$ and $\mathrm{HCHO}$ time profiles is visible, reflecting similar removal pathways from $\mathrm{OH}$ and photolysis, as well as dilution for these gases.

\subsection{Statistical modeling results at CENICA}

Statistical tests were performed to determine the mathematical transformation that yielded best correlations for both approaches. As the best model for the $\mathrm{CO}-\mathrm{O}_{3}$ tracer pair, a square root transformation was identified $\left(r^{2}=0.53\right.$, see Table 1), while the CO-CHOCHO tracer pair was best fit using a linear relation $\left(r^{2}=0.76\right.$, see Table 1$)$, covering both the Easter and non-Easter weeks. Table 2 shows results of these regression tests for the tested mathematical transformations. A comparison between the measured and fitted concentration time profiles of ambient $\mathrm{HCHO}$ concentrations is shown in Fig. 3. It is possible to observe that $\mathrm{HCHO}$ modeled by $\mathrm{CO}-\mathrm{CHOCHO}$ pair follows more accurate the diurnal profile than the $\mathrm{HCHO}$ obtained by $\mathrm{CO}-\mathrm{O}_{3}$ pair (see Fig. 4). Also in the scatter plots the confidence interval area are smaller in the $\mathrm{CO}-\mathrm{CHOCHO}$ pair than $\mathrm{CO}-\mathrm{O}_{3}$ pair, finally the $r^{2}$ coefficients are superior for $\mathrm{CO}-\mathrm{CHOCHO}$ pair than $\mathrm{CO}-\mathrm{O}_{3}$.

A summary of results and the statistical significance of the multiple regression analysis for the $\mathrm{CO}-\mathrm{CHOCHO}$ tracer pair (Eq. 1) are presented in Table 2. This table also shows the coefficients from the entire campaign, before, during and after Easter week. In order to compare results the analysis was run using subsets of data, which comprise about comparable number of data points for each time period considered (about 2 days). By dividing the data in 3 periods of interest, it is possible to improve the $r^{2}$-values, and lower the residual $\beta_{0}$ values, suggesting that the $\beta$-values are not fixed, but vary from day to day. 


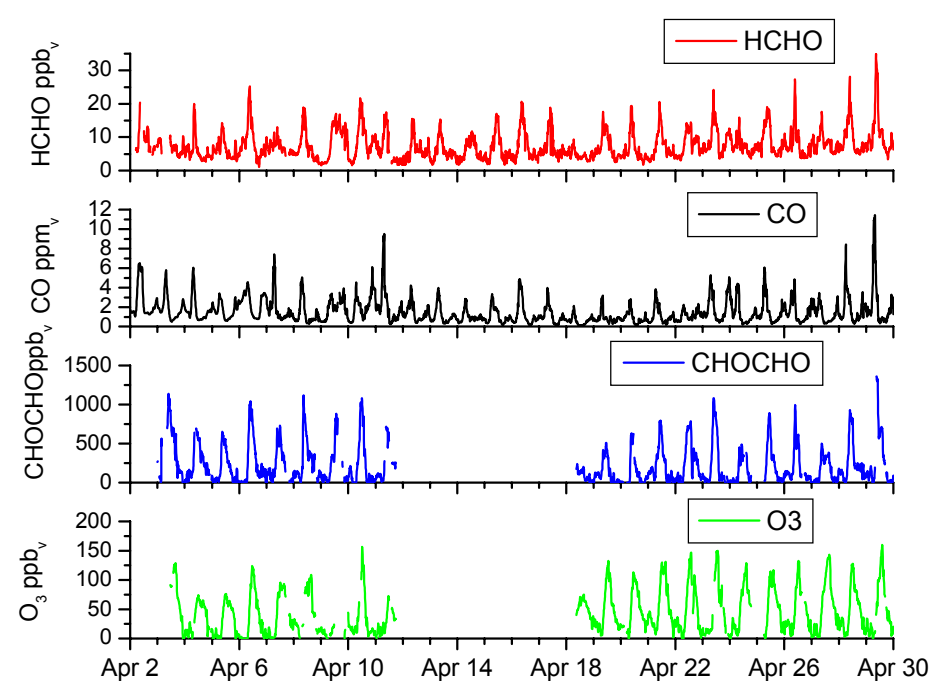

(a)

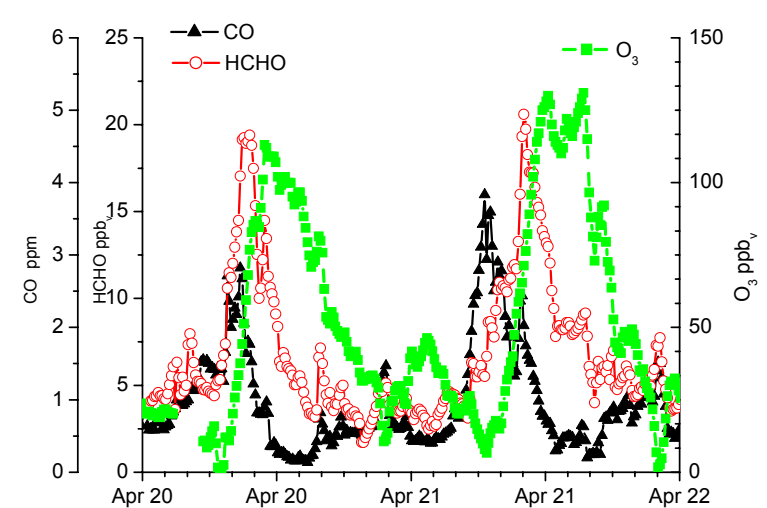

(b)

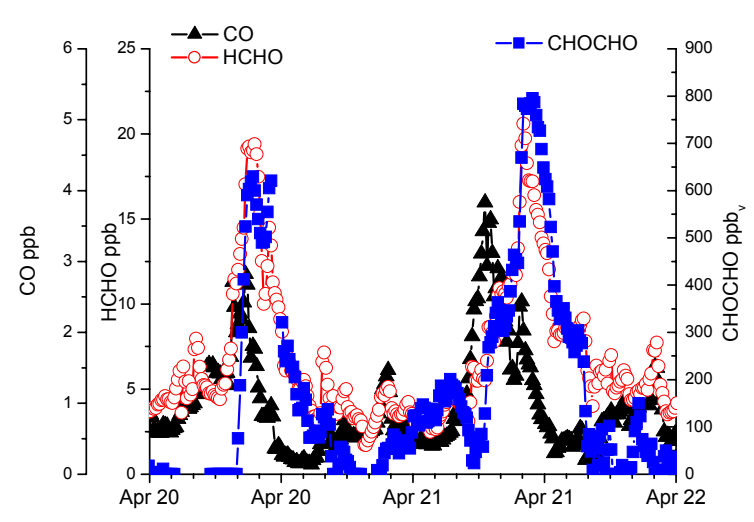

(c)

Fig. 2. Time series plots of $\mathrm{O}_{3}, \mathrm{HCHO}, \mathrm{CHOCHO}$ and $\mathrm{CO}$ measured in CENICA supersite during April 2003. Times is in UTC, each day is marked with 0 and $12 \mathrm{~h}$.

In an attempt to characterize the day-by-day variability in the $\beta$-values, daily subsets of data were analyzed using the $\mathrm{CO}-\mathrm{CHOCHO}$ tracer pair. Of the 24 days analyzed, only 13 days met the quality assurance criteria to be considered in this analysis, i.e. had a minimum of $17 \mathrm{~h}$ of data coverage per day, and $r^{2}>0.7$. The average ratio of primary $\mathrm{HCHO}$ to $\mathrm{CO}$ determined from individual days $\left(0.005 \pm 0.001 \mathrm{ppb}_{v} / \mathrm{ppb}_{v}\right)$ and the ratio of secondary HCHO to $\mathrm{CHOCHO}\left(0.040 \pm 0.026 \mathrm{ppb}_{v} / \mathrm{ppb}_{v}\right)$ both agree within error-limits with the value derived from the global data-set (see Table 1). The $\beta_{1}$ and $\beta_{2}$ parameters were found to be independent of each other, and no correlations with traffic counts, temperature and wind speed were observed. Also, the $\mathrm{HCHO}$ background was found independent from traffic counts and wind speed. All significant correlations are shown in Fig. 5. Significant correlations were observed for the
HCHO background with $\beta_{1}, \beta_{2}$ (both negative correlations), $\mathrm{O}_{3}$ and temperature (both positive correlations). The negative correlations of the HCHO background with $\beta_{1}$ and $\beta_{2}$ reflect lower $\beta_{0}$-parameters during days, when stronger coupling of the ambient $\mathrm{HCHO}$ with the primary and secondary indicator molecules is observed, in general agreement with the interpretation of $\beta_{0}$ as a residual $\mathrm{HCHO}$ concentration. The positive correlations of $\mathrm{HCHO}$ background with $\mathrm{O}_{3}$ and temperature are indicative of some effect during conditions favorable for photochemical activity, which may either point to a possible role of the $\mathrm{HCHO}$ background in promoting photochemical smog, or be an indication for higher HCHO concentrations during days of more active photochemistry, where imperfections in the approach are likely to become more significant, or both. 
Table 1. Result from different linear regressions using different data transformations.

\begin{tabular}{lcccccccc}
\hline & \multicolumn{3}{c}{$\mathrm{CO}-\mathrm{HCHO}-\mathrm{O}_{3}$} \\
& $\beta_{1}$ & $\beta_{2}$ & $\beta_{0}$ & $R^{2}$ & $\beta_{1}$ & $\beta_{2}$ & $\beta_{0}$ & $r^{2}$ \\
\hline Linear & 0.064 & 0.002 & 1.69 & 0.41 & 0.014 & 0.0015 & 2.4 & 0.76 \\
ln & 0.290 & 0.569 & -3.06 & 0.45 & 0.221 & 0.390 & -1.85 & 0.53 \\
Sqrt & 0.167 & 0.042 & 0.17 & 0.53 & 0.060 & 0.027 & 1.01 & 0.69 \\
$x^{2}$ & $5.89 \mathrm{E}-03$ & $3.22 \mathrm{E}-06$ & 47.785 & 0.14 & $3.80 \mathrm{E}-04$ & $2.78 \mathrm{E}-06$ & 30.329 & 0.73 \\
$x^{3}$ & $5.11 \mathrm{E}-04$ & $3.84 \mathrm{E}-09$ & 844.194 & 0.03 & $9.27 \mathrm{E}-06$ & $3.77 \mathrm{E}-09$ & 334.178 & 0.71 \\
$1 / x$ & $2.64 \mathrm{E}-03$ & 38.441 & 0.123 & 0.12 & $6.15 \mathrm{E}-03$ & 38.968 & 0.116 & 0.13 \\
$1 / \ln (x)$ & $7.87 \mathrm{E}-04$ & 5.505 & -0.215 & 0.07 & $3.78 \mathrm{E}-02$ & 5.464 & -0.230 & 0.07 \\
$1 / \operatorname{sqrt}(x)$ & 0.102 & 4.525 & 0.229 & 0.21 & 0.158 & 4.213 & 0.236 & 0.24 \\
$1 / x^{2}$ & $-2.77 \mathrm{E}-05$ & 2019.471 & 0.033 & 0.02 & $-1.34 \mathrm{E}-04$ & 1982.638 & 0.030 & 0.02 \\
$1 / x^{3}$ & $-7.96 \mathrm{E}-07$ & 50016.25 & 0.010 & 0.00 & $-4.61 \mathrm{E}-06$ & 50232.12 & 0.009 & 0.00 \\
\hline
\end{tabular}

Table 2. Model Results using the CO-CHOCHO tracer pair.

\begin{tabular}{lccccc}
\hline & $\beta_{1}$ & $\beta_{2}$ & $\beta_{0}$ & $r^{2}$ & N. Obs \\
\hline Pre Easter & $0.0143 \pm 0.0005$ & $0.0017 \pm 0.00011$ & $1.44 \pm 0.31$ & 0.77 & 257 \\
Easter & $0.0197 \pm 0.0008$ & $0.0027 \pm 0.00021$ & $1.33 \pm 0.17$ & 0.90 & 256 \\
Post Easter & $0.0149 \pm 0.0006$ & $0.0024 \pm 0.00014$ & $1.75 \pm 0.23$ & 0.84 & 264 \\
\hline
\end{tabular}

In an attempt to assess whether differences in the atmospheric lifetime of $\mathrm{HCHO}$ and $\mathrm{CHOCHO}$ affect the results, corrections to $\mathrm{CHOCHO}$ and $\mathrm{HCHO}$ due to $\mathrm{OH}$ and photolysis loss were made (Eq. 5). The time intervals for integration, $\Delta t$, was varied from 1 to $120 \mathrm{~min}$, and corresponding corrections in the concentrations of $\mathrm{HCHO}$ and $\mathrm{CHOCHO}$ varied from $10 \%$ and $13 \%$ ( $1 \mathrm{~min})$ to $74 \%$ and $192 \%$ (120 $\mathrm{min})$. Use of the loss-corrected time series of $\mathrm{HCHO}$ and $\mathrm{CHO}-$ CHO tended to improve the $r^{2}$-values (from 0.76 to 0.8 in global analysis), but did not significantly affect the percent fractions of primary and secondary HCHO. Those improvements reflect a lower $\mathrm{HCHO}$ background concentration of about $5 \%$.

A series of sensitivity tests were carried out, where a variable offset-concentrations (between 10 to $150 \mathrm{pptv}$ ) was added to the ct-profile of glyoxal to reflect measurement uncertainties in glyoxal concentrations. Additionally, in some runs a modified ct-profile of $\mathrm{CO}$ was used to reflect a possible influence that arises from the vertical mixing of air masses. Air from aloft the planetary boundary layer (PBL) mixes into the PBL during the morning, and likely has a different $\mathrm{HCHO} / \mathrm{CO}$ ratio that would create a bias in the model. These corrections (Eq. 6) decrement the measured $\mathrm{CO}$ concentration, and were generally small, i.e. $0-2 \%$ between 5:00 to 9:00 am, and up to $12 \%$ around noon time. The results from these sensitivity tests are summarized in Fig. 6, where the percent contribution of primary, secondary and background $\mathrm{HCHO}$ from individual runs are plotted as a function of the $\beta_{0}$-parameter. While the percent fraction of primary $\mathrm{HCHO}$ was found to be almost constant, the percent fractions of background and secondary $\mathrm{HCHO}$ contributions are anti-correlated, and scale linearly with the $\beta_{0^{-}}$ parameter. The fact that secondary $\mathrm{HCHO}$ decreases as the background HCHO increases, suggests a relation of the $\beta_{0^{-}}$ parameter with photochemistry rather than emission sources. Furthermore, weak negative correlations of the percent fraction of secondary $\mathrm{HCHO}$ with $\mathrm{O}_{3}$ and temperature were observed (despite no such relation was observed for the $\beta_{1}$ and $\beta_{2}$ parameters). For both parameters, the percent fraction of secondary $\mathrm{HCHO}$ showed essentially no variation at low temperatures (below 20 C) and moderately low $\mathrm{O}_{3}$ (below $110 \mathrm{ppbv}$ ), but tended to decrease for higher values of temperature and $\mathrm{O}_{3}$. This is taken as an indication that at least during days of intense photochemistry, the $\beta_{0}$-parameter is at least partly affected by remaining imperfections in the $\mathrm{CO}-\mathrm{CHOCHO}$ tracer approach. This also introduces a slight bias in the interpretation of $\beta_{0}$-parameter as $\mathrm{HCHO}$ background, indicating that at least some of the HCHO background is in fact erroneously interpreted secondary $\mathrm{HCHO}$. Such HCHO could be form from the photochemistry of anthropogenic VOC which may not form $\mathrm{CHOCHO}$, or be the result of advected air masses that are depleted in $\mathrm{CHOCHO}$ during transport. The $r^{2}$ values from the statistical analysis indicate the proportion of $\mathrm{HCHO}$ mixing ratio measure- 

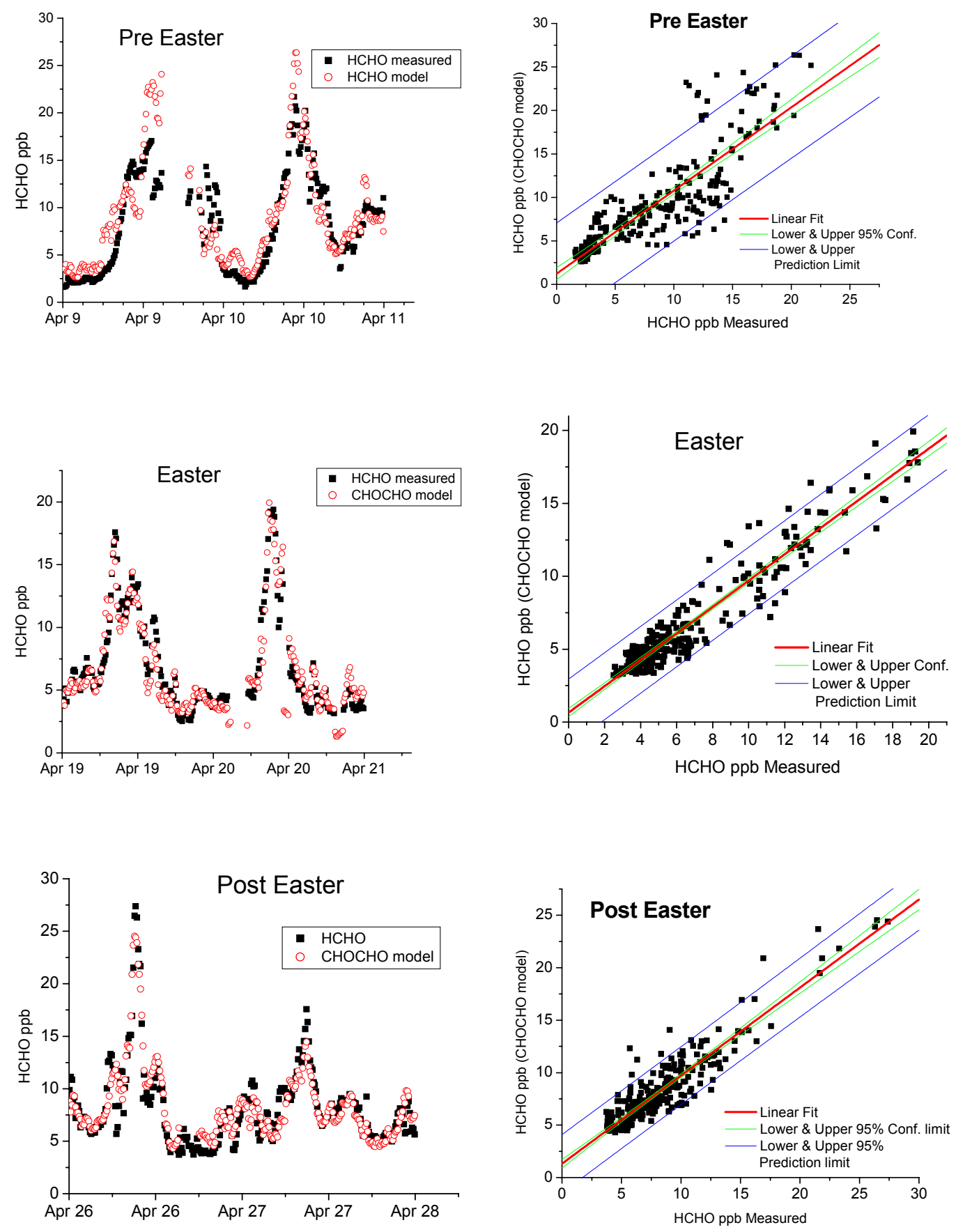

Fig. 3. Comparison between $\mathrm{HCHO}$ measured and fitted values from statistical regression of HCHO-CO-CHOCHO data for each time period. Upper row shows results from pre-Easter week, center row for Easter week and bottom for post-Easter week. In the scatter plots shadow present the $95 \%$ confidence interval for each regression. Pre Easter week has $r^{2}=0.77$, Easter week 0.90 and post Easter $r^{2}=0.85$.

ments that can be predicted by the regression model (Green, 1998). The results in Table 2 indicate that this proportion is in all cases well above $75 \%$, and up to $90 \%$, reflecting that the CO-CHOCHO tracer pair - while not perfect - generally replicates well the observations.
Using the Eqs. (2), (3) and (4) it is possible to compute the ct-profiles of the percentage of primary, secondary and background $\mathrm{HCHO}$. Figure 7 shows the diurnal profiles of the contribution of primary, secondary and background $\mathrm{HCHO}$ before, during and after Easter week. For each time period, primary $\mathrm{HCHO}$ is the dominant source of $\mathrm{HCHO}$ in 

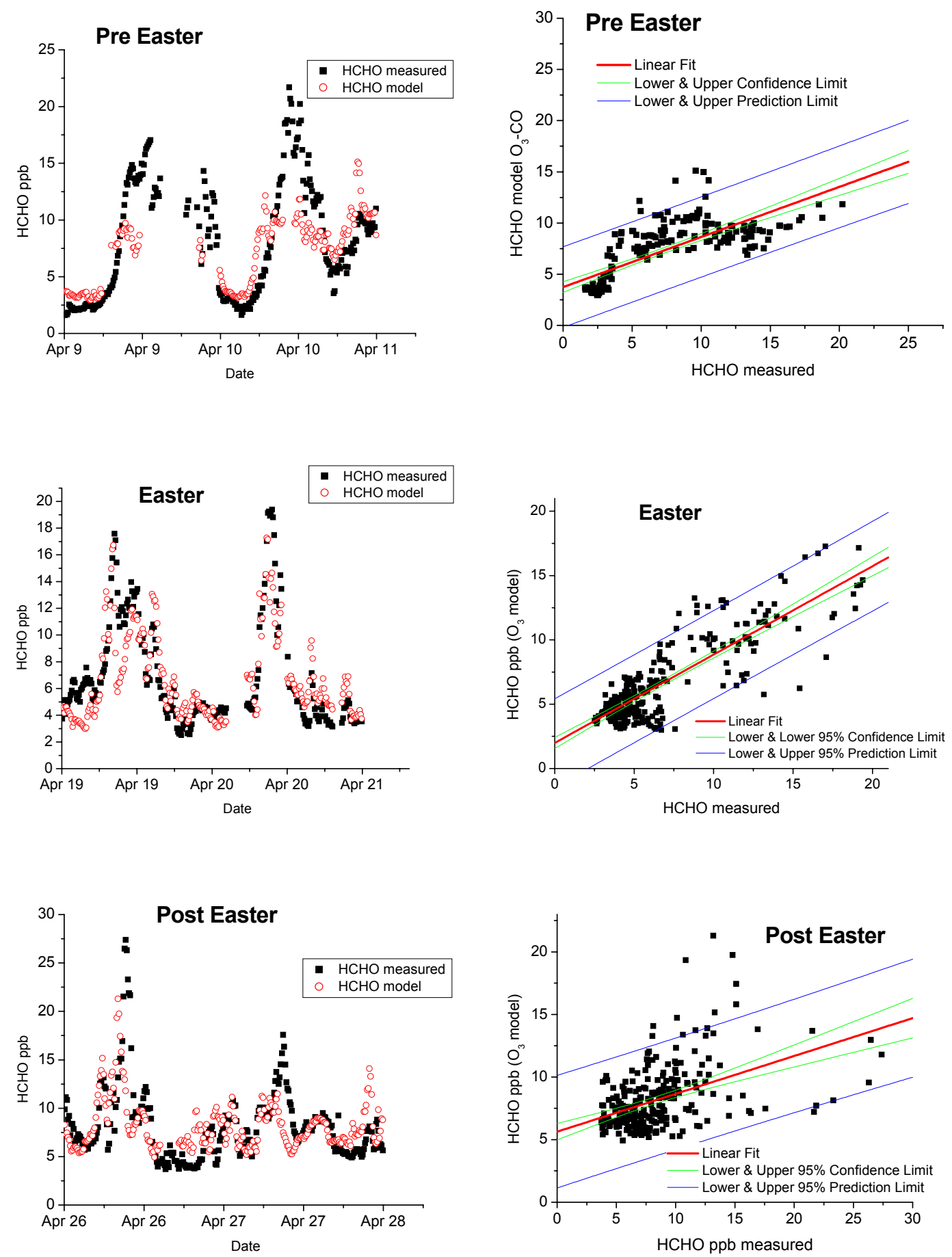

Fig. 4. Comparison between $\mathrm{HCHO}$ measured and fitted values from statistical regression models using $\mathrm{HCHO}-\mathrm{CO}-\mathrm{O}_{3}$ for each time period. Upper row shows results from pre-Easter week, center row for Easter week and bottom for post-Easter week. In the scatter plots shadow present the 95\% confidence interval for each regression. Pre Easter week has $r^{2}=0.44$, Easter week 0.74 and post Easter $r^{2}=0.47$.

the early morning hours (before 8:00 am). The photochemistry of VOC becomes active about one hour after sunrise (Volkamer et al., 2005b), and becomes the dominant source of HCHO around 8:30 am, slightly earlier under the traffic conditions of Easter week. Secondary HCHO is the domi- nant source for most of the day, until in the late afternoon primary sources gain relative importance and become comparable around $3-5 \mathrm{pm}$. Primary $\mathrm{HCHO}$ is the dominant source in the late afternoon and at night. The percent fractions of different sources contributing to ambient $\mathrm{HCHO}$ concentra- 


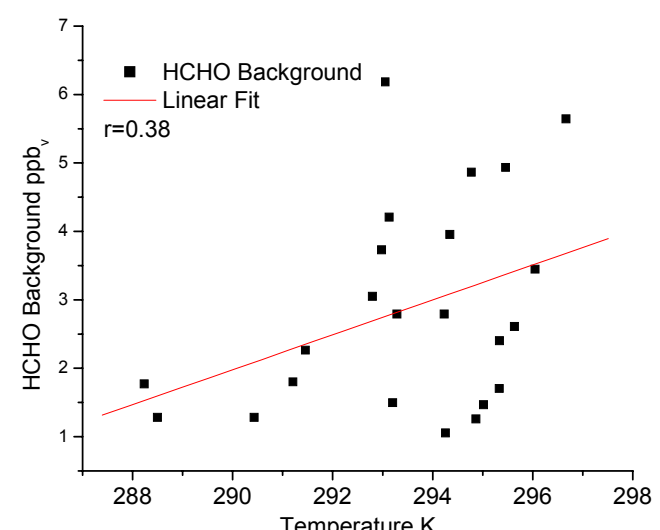

(a)

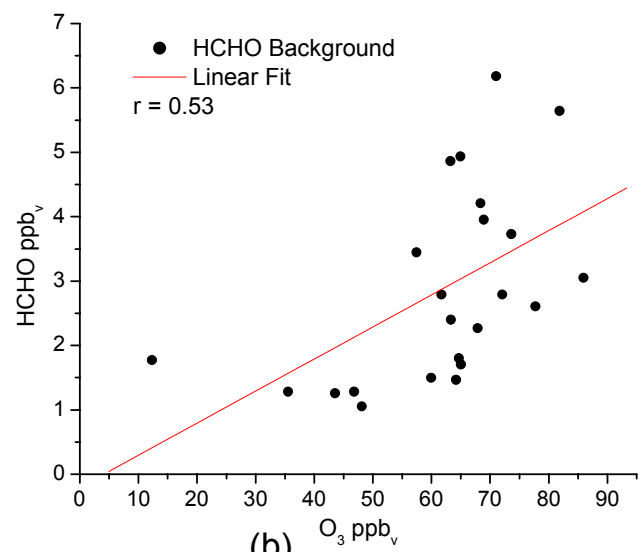

(b)

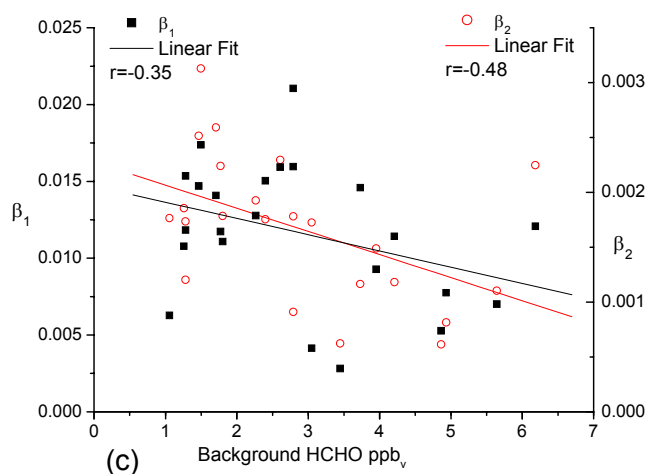

Fig. 5. Correlation of $\mathrm{HCHO}$ background vs. temperature (a) and $\mathrm{O}_{3}$ concentration (b). Positive correlation is observed. In panel (c) coefficients $\beta_{1}, \beta_{2}$ from Eq. (1) vs. HCHO background concentration.

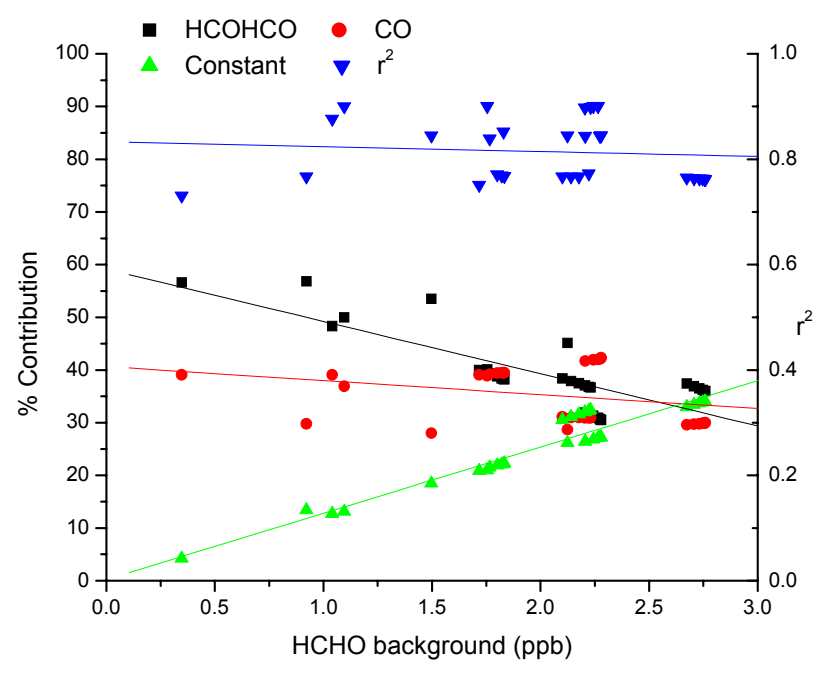

Fig. 6. Percent-contributions from photochemistry, emissions and the background as a function of background concentration.
Table 3. Contributions of photochemistry and emissions to ambient $\mathrm{HCHO}$.

\begin{tabular}{lccc}
\hline & \multicolumn{2}{c}{ Secondary } & Primary \\
\hline & CHOCHO & Const & CO \\
Pre Easter & $41.0 \pm 6.5$ & $17.5 \pm 6.5$ & $41.5 \pm 0.2$ \\
Easter & $38.9 \pm 7.1$ & $23.7 \pm 6.8$ & $37.5 \pm 0.3$ \\
Post Easter & $33.5 \pm 6.9$ & $20.9 \pm 4.8$ & $45.6 \pm 2.1$ \\
Global average & $37.8 \pm 6.8$ & $20.7 \pm 6.0$ & $41.5 \pm 0.8$ \\
4:00-14:00 Average & $42.3 \pm 2.9$ & $18.1 \pm 1.45$ & $39.6 \pm 1.6$ \\
\hline
\end{tabular}

tions are listed for the investigated time-periods in Table 3. On average, the contributions of primary, secondary and unaccounted sources (background) to ambient HCHO concentrations (on a $24 \mathrm{~h}$ basis) were $42 \%, 38 \%$ and $21 \%$. Respectively using an average from 4:00 to 14:00 - this covers rushhour and photochemistry, but excludes venting and recirculation within the MCMA - as we can see the contributions are comparable. 

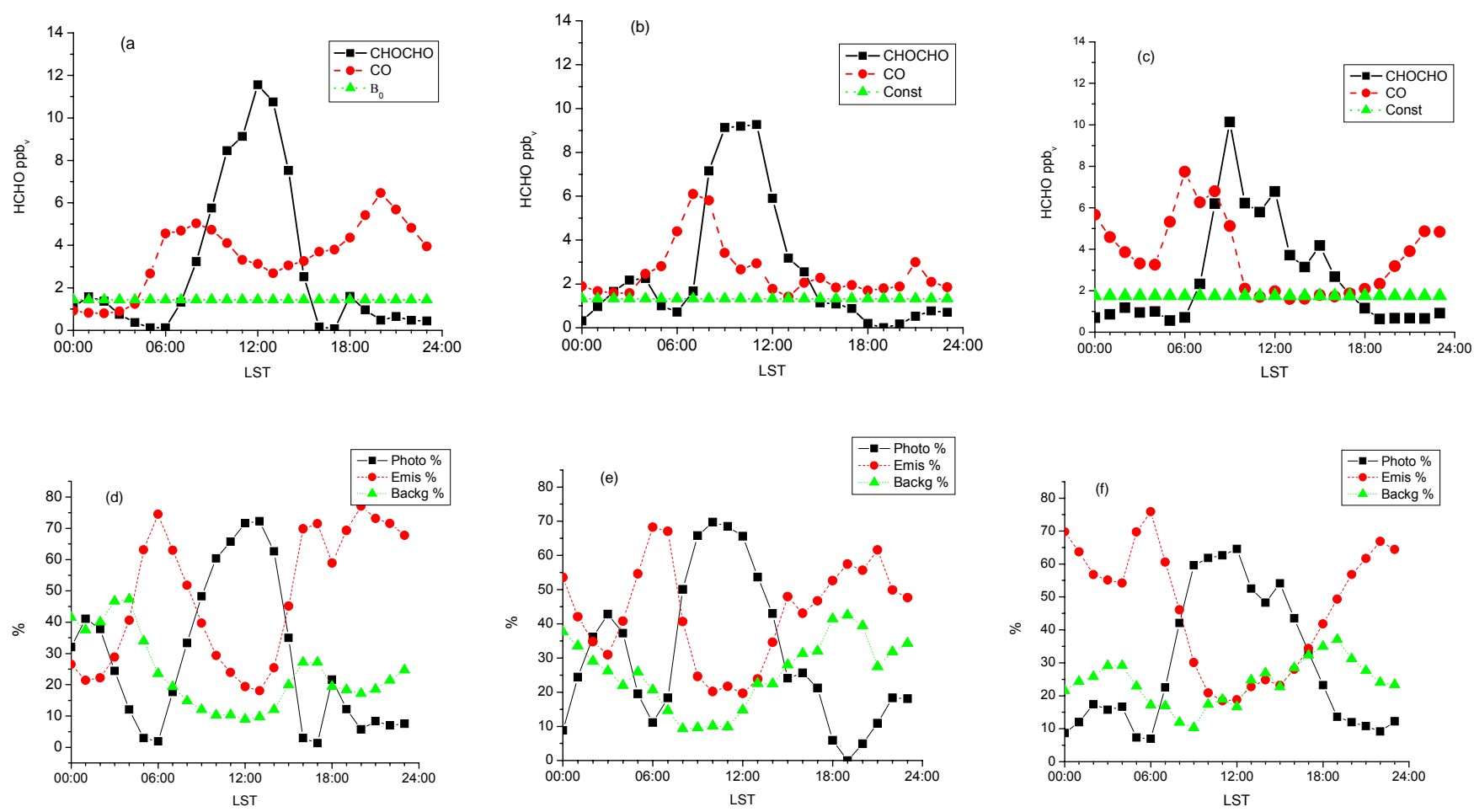

Fig. 7. Average diurnal contributions of primary, secondary and residual HCHO to ambient HCHO for three time periods: before (left), during (middle), after (right) Easter week. The top row of panels gives contributions in units of ppbv, and lower row of panels in percent contributions to ambient $\mathrm{HCHO}$.

Primary $\mathrm{HCHO}$, emitted during early morning hours will help "jump start" photochemistry since formaldehyde photolysis is a major source of prompt radical production in the MCMA (Volkamer et al., 2005 $\mathrm{a}^{1}$ ). The resulting photochemistry will be enhanced, causing more effective VOC oxidation and, therefore, more photochemical $\mathrm{HCHO}$ production. Thus, the emitted HCHO fraction and its photochemical production fraction are not decoupled, and it will require a comprehensive photochemical modeling study to determine degree of coupling.

\subsection{Application to mobile laboratory measurements at other the MCMA sites}

The coefficients determined for the $\mathrm{CO}-\mathrm{O}_{3}$ tracer pair were applied to the simultaneous measurements of $\mathrm{HCHO}, \mathrm{CO}$ and $\mathrm{O}_{3}$ sampled on board the ARI mobile laboratory at CENICA, and three additional fixed sites, in Merced, Pedregal and Santa Ana to assess the spatial distribution of the background HCHO concentration within the MCMA. The approach in this analysis was to use the global $\beta_{1}$ and $\beta_{2}$ coefficient (approach 1, linear model) determined from the open path measurements at CENICA to subtract primary and secondary $\mathrm{HCHO}$ from the ambient $\mathrm{HCHO}$ data collected by ARI mobile laboratory. The background HCHO is defined as the difference between the measured $\mathrm{HCHO}$ and the inferred contributions from direct (determined by measured $\mathrm{CO}$ ) and photochemical (determined by measured $\mathrm{O}_{3}$ ) sources was calculated as:

$$
\begin{aligned}
& {[\mathrm{HCHO}]^{\text {background }}=[\mathrm{HCHO}]^{\text {measured }}} \\
& \quad-\left(0.063\left[\mathrm{O}_{3}\right]^{\text {measured }}+0.0028[\mathrm{CO}]^{\text {measured }}\right)
\end{aligned}
$$

The background $\mathrm{HCHO}$ values, determined via this analysis are depicted in Fig. 8 for several sites throughout the city. The red triangles represent fixed sites where a full diurnal pattern of $\mathrm{HCHO}, \mathrm{O}_{3}$ and $\mathrm{CO}$ was available for analysis. The other black circles, in Fig. 8, represent selected mobile measurements where the ambient concentrations were not grossly influenced by primary emissions. Each of the points includes approximately $30 \mathrm{~min}$ of data, the resulting background $\mathrm{HCHO}$ concentration is portrayed by the size of the data point. This analysis approach must be caveated with a couple of remarks. First, the site-to-site variability of the $\beta$ parameters is assumed to be nil. This would be problematic if the $\mathrm{HCHO} / \mathrm{CO}$ emission ratio for traffic typical of the sampling footprint at CENICA was very different from that at the other fixed sites. Second, the sampled airmasses in the mobile laboratory are often influenced by very "fresh" emissions. These emissions are not in photochemical equilibrium to the same extent that the open path CENICA airmass is which determined the $\beta$ parameters used. Finally, 
the focus of this paper is the treatment of the superior glyoxal - carbon monoxide tracer pair, but because a glyoxal measurement was not available on the mobile laboratory, the $\mathrm{O}_{3}$-CO pair was used in order to examine the potential spatial variability in the parameter interpreted as "background" formaldehyde.

The first observation is that the CENICA openpath HCHO background concentration (between 1.5 and $2.4 \mathrm{ppbv}$ ) for the whole campaign, agrees within error limits with the application of the $\mathrm{CO}-\mathrm{O}_{3}$ tracer data $(3.7 \mathrm{ppbv})$ to the mobile laboratory data at CENICA. The data from the other sites indicate there may be a decrease in the background $\mathrm{HCHO}$ with increasing distance from the city center. For example at Santa Ana, located well to the south of the city, the background $\mathrm{HCHO}$ drops to about 1 ppbv.

The pattern in the mobile data is not as clear. The difficulty in applying the $\mathrm{CO}-\mathrm{O}_{3}$ tracer pair to mobile data lies with the direct emissions of NO from mobile sources. The influence of primary $\mathrm{NO}$ on $\mathrm{NO}_{x}$ partitioning and $\mathrm{O}_{3}$ pushes the system away from the presumed photochemical equilibrium. Typically, the presence of any automobile or truck traffic within $50 \mathrm{~m}$ upwind influences the $\mathrm{CO}$ and NOx concentrations measured by the mobile laboratory. As a result, most of the on-road data has not been included in this analysis.

The spatial difference in background HCHO in MCMA suggests the presence of direct $\mathrm{HCHO}$ emissions within the city that do not have a concomitant $\mathrm{CO}$ emission. The additional HCHO could be coming directly from certain adhesives used in wood products, insect and fungus control products, corrosion inhibitors in metal processing facilities as well as numerous other industrial applications, and may increase the value of background $\mathrm{HCHO}$ inside the city relative to the Santa Ana site.

\subsection{Comparison of primary vs. secondary $\mathrm{HCHO}$ from the literature}

Previous studies employed a range of techniques to separate primary and secondary formation of HCHO (Li et al., 1997) employed principal component analysis, and found the portion of primary $\mathrm{HCHO}$ about $20 \%$ during summer near Vancouver, Canada. Possanzini et al. (2002) compared the ratio of $\mathrm{HCHO} /$ toluene in fresh emissions and ambient air in Rome, Italy, and found that secondary $\mathrm{HCHO}$ accounted for $80-90 \%$ in the summer, while this portion fell below $35 \%$ in the winter. Friedfeld et al. (2002) used the $\mathrm{O}_{3}$-CO tracer pair, and found secondary $\mathrm{HCHO}$ to account for roughly $63 \%$ of ambient HCHO during June 2000 in Houston, TX. Jiménez et al. (2005) used the $\mathrm{O}_{3}-\mathrm{NO}_{\mathrm{x}}$ tracer pair to separate secondary and primary $\mathrm{HCHO}$ and find on average $80 \%$ secondary $\mathrm{HCHO}$, consistent with a photochemical model during summer in Grenoble, France. None of these studies address the issue of residual HCHO in their analysis, which is expected highest during times of low photochemical activity. In this study, despite active photochemistry and the improve-

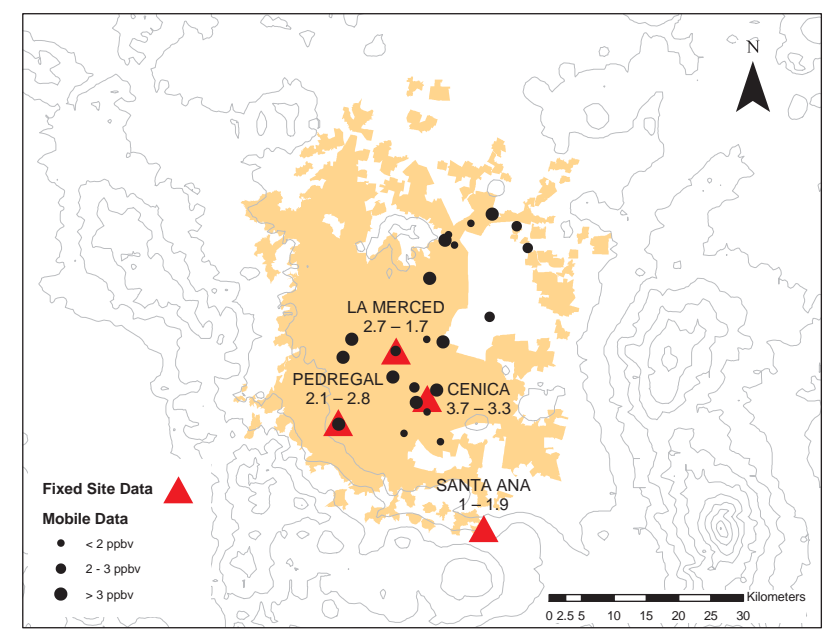

Fig. 8. Apparent background $\mathrm{HCHO}$ using the $\mathrm{CO}$ and $\mathrm{O}_{3}$ correlations. The circular data points represent "mobile data" periods where sampling criteria indicated a "background" ambient $\mathrm{HCHO}$ estimate could be attempted. The larger diamonds represent stationary site data. See text for additional details.

ments in the tracer pair used, residual HCHO accounts for a non-negligible $20 \%$ of ambient HCHO. Even if all this portion was counted as secondary $\mathrm{HCHO}$ (in sum 58\%), the portion of primary $\mathrm{HCHO}(42 \%)$ in Mexico City is higher than in any previous study conducted during a time of year when photochemistry was comparable and active.

\section{Conclusions}

A statistical regression model has been employed to separate ambient $\mathrm{HCHO}$ concentrations into contributions from mobile emission sources (primary $\mathrm{HCHO}$ ) and the airborne source from volatile organic compound (VOC) photochemistry (secondary $\mathrm{HCHO}$ ). Two sets of tracer molecules were employed, and their performance is compared. In both cases $\mathrm{CO}$ was used as an indicator for primary $\mathrm{HCHO}$. As indicator for secondary $\mathrm{HCHO}$ we used $\mathrm{O}_{3}$ in once case, and in the other case employ a novel indicator molecule, glyoxal (CHOCHO, the simplest $\alpha$-dicarbonyl), for which direct time-resolved measurements have recently been demonstrated (Volkamer et al., 2005b). Analyses were performed for three separate time-regimes: (1) before, (2) during, and (3) after Easter week.

The CO-CHOCHO tracer pair is found to better represent ambient $\mathrm{HCHO}$ concentrations than the $\mathrm{CO}-\mathrm{O}_{3}$ tracer pair. This is attributed to the efficient titration reaction of $\mathrm{O}_{3}$ with NO from traffic emissions, as well as the rather indirect link of $\mathrm{O}_{3}$ and secondary $\mathrm{HCHO}$ forming VOC chemistry, which is highly non-linear. In general, the CO-CHOCHO tracer pair is found to explains a larger portion of ambient $\mathrm{HCHO}$ (up to $90 \%$ ). Also, this tracer pair explains ambient $\mathrm{HCHO}$ best 
by using a rather intuitive "linear" model, which represents ambient $\mathrm{HCHO}$ as a linear combination of $\mathrm{CO}$ and $\mathrm{CHO}-$ $\mathrm{CHO}$ concentrations. The amount of HCHO not accounted for by the $\mathrm{CO}-\mathrm{CHOCHO}$ tracer pair (unaccounted $\mathrm{HCHO}$ ) tends to be lower than for the $\mathrm{CO}-\mathrm{O}_{3}$ tracer pair, and only for the former pair of tracers is "background $\mathrm{HCHO}$ " in general agreement with measured concentrations of $\mathrm{HCHO}$ outside the MCMA.

Reduced traffic intensity during Easter week results in a reduction in the percent contributions of primary $\mathrm{HCHO}$; it affects the percent contribution of secondary $\mathrm{HCHO}$ to a lesser extent. In all cases studied, diurnal variations of the percent-contributions of primary $\mathrm{HCHO}$ peak before sunrise, when primary $\mathrm{HCHO}$ accounts for up to $80 \%$ of the source of ambient HCHO. Shortly after sunrise, secondary HCHO sources rapidly gain importance, and become comparable to primary sources within few hours. Secondary HCHO sources are the largest daytime $\mathrm{HCHO}$ source for ambient $\mathrm{HCHO}$, accounting for up to $80 \%$ of ambient $\mathrm{HCHO}$ sources before and around solar noon (1:45 pm). In the later afternoon (3:00 to 5:00 pm) primary sources gain relative importance, and are the dominant source at night.

Direct emissions from not combustion related sources (e.g. from industrial processing) may not be correlated with the indicator molecules used in this study, and may be in part responsible for some of the up to $21 \%$ of unaccounted HCHO. These unaccounted HCHO sources are responsible for about a 2 ppbv HCHO "background" concentration throughout the MCMA. However, analyses indicate this unaccounted HCHO may be at least in part, due to unaccounted secondary HCHO (e.g. due to VOC photochemistry that forms $\mathrm{HCHO}$ but not $\mathrm{CHOCHO}$ ). This derived contribution of secondary $\mathrm{HCHO}$ is a lower limit, and the percentage of unaccounted $\mathrm{HCHO}$ sets an upper limit to the relative importance of industrial emission sources of HCHO in the MCMA. On a $24 \mathrm{~h}$ average basis, for the contributions to ambient $\mathrm{HCHO}$ from primary, secondary and unaccounted sources were $42 \%,>38 \%$ and $<21 \%$, respectively.

A very important portion of the ambient $\mathrm{HCHO}$ measured during the MCMA-2003 campaign is related to mobile source emissions. Positive feed-backs from reductions in primary $\mathrm{HCHO}$ sources to yield reductions also in secondary $\mathrm{HCHO}$ sources are expected, and deserve further investigation.

Acknowledgements. This research was supported by funding from the Mexican Metropolitan Environmental Commission, the US National Science Foundation (ATM- 308748) and the Alliance for Global Sustainability. R. V. acknowledges a postdoctoral fellowship by the Henry and Camille Dreyfus Foundation. We are grateful to V. H. Paramo and R. Ramos for their help in obtaining traffic count data and to Enrique Gonzalez-Villaseñor from Dirección de Operación y Tránsito e Ingeniería (Secretaria de Seguridad Publica) and INMER SA de CV magnetic traffic counters operator. We thank C. Pastor for help with the GIS work and W. Brune from $\mathrm{OH}$ data.
Edited by: U. Pöschl

\section{References}

Altshuller, A. P.: Production of aldehydes as primary emissions and from secondary atmospheric reactions of alkenes during the night and early morning hours, Atmos. Environ. 27A, 21-32, 1993.

Anderson, L. G., Janning, J. A., Barrell, R., Miyagishima, J., Jones, R. H., and Wolfe, P.: Sources and sinks of formaldehyde and acetaldehyde: an analysis of Denvers ambient concentration data, Atmos. Environ., 30(12), 2114-2123, 1996.

Atkinson, R.: Atmospheric chemistry of VOCs and NOx, Atmos. Environ., 34, 2063-2101, 2000.

Box, G., Jenkings, G., and Reinsel, G.: Time Series Analysis: Forecasting and Control, Pretince-Hall, Englewood Cliffs, NJ, 1994.

Canagaratna, M. R., Jayne, J. T., Ghertner, A., Herndon, S. C., Shi, Q., Jimenez, J. L., Silva, P., Williams, P., Lanni, T., Drewnick, F., Demerjian, K. L., Kolb, C. E., and Worsnop, D. R.: Chase Studies of Particulate Emissions from in-use New York City Vehicles, Aerosol Sci. Technol, 38, 555-573, 2004.

Carlier, P., Hannachi, H., and Mouvier, G.: The chemistry of carbonyl compounds in the atmosphere, Atmos. Environ., 20, 20792099, 1986.

Carter, W. P. L.: Computer Modeling of Environmental Chamber Measurements of Maximum Incremental Reactivities of Volatile Organic Compounds, Atmos. Environ., 29, 2513-2527, 1995.

Dean J.: Lange's handbook of chemistry, 13th ed. New York, NY, McGraw-Hill, 1985.

Dodge, M. C.: Formaldehyde production in photochemical smog as predicted by three state-of-the-science chemical oxidant mechanisms, J. Geophys. Res., 95, 3635-3648, 1990.

Dunlea, E. J., Herndon, S. C., Nelson, D. D., Volkamer, R. M., Lamb, B. K., Allwine, E. J., Grutter, M., Ramos Villegas, C. R., Marquez, C., Blanco, S., Cardenas, B., Kolb, C. E., Molina, L. T., and Molina, M. J.: Technical note: Evaluation of standard ultraviolet absorption ozone monitors in a polluted urban environment, Atmos. Chem. Phys., 6, 3163-3180, 2006, http://www.atmos-chem-phys.net/6/3163/2006/.

Finlayson-Pitts, B. J. and Pitts, J. N.: Atmospheric Chemistry, Wiley, New York, 1986.

Friedfeld, S., Fraser, M., Ensor, K., et al.: Statistical analysis of primary and secondary atmopsheric formaldehyde, Atmos. Environ., 36, 477-4775, 2002.

Granby, K., Christensen, C. S., and Lohse, C.: Urban and semi-rural observations of carboxylic acids and carbonyls, Atmos. Environ., 35, 2096-2106, 1997.

Green, W. H.: Econometric Analysis, 3rd Ed. Pretince Hall Inc., 1998.

Grutter, M., Flores, E., Andraca-Ayala, G., and Baez, A.: Formaldehyde levels in downtown Mexico City during 2003, Atmos. Environ., 39, 1027-1034, 2005.

Herndon, S. C., Shorter, J. H., Zahniser, M. S., Nelson, D. D. J., Jayne, J. T., Brown, R. C., Miake-Lye, R. C., Waitz, I. A., Silva, P., Lanni, T., Demerjian, K. L., and Kolb, C. E.: NO and $\mathrm{NO}_{2}$ Emissions Ratios Measured from in use Commercial Aircraft during Taxi and Take-Off, Environ. Sci. Technol., 38, 60786084, 2004.

Herndon, S. C., Yongquan, L., Nelson, D. D., and Zahniser, M. S.: Determination of line strenghs for selected transitions in the 
$v_{2}$ band relative to the $\mathrm{U}_{1}$ and $\mathrm{N}_{2}$ bands of $\mathrm{H}_{2} \mathrm{CO}, \mathrm{J}$. Quant. Spectros. Rad. Transfer, 90, 207-216, 2005.

Hoekman, S. K.: Speciated measurements and calculated reactivities of vehicle exhaust emissions from conventional and reformulated gasolines, Envir. Sci. Technol., 26, 1206-1216, 1992.

Kean, A. J., Grosjean, E., Grosjean, D., and Harley, R. A.: OnRoad Measurement of Carbonyls in California Light-Duty Vehicle Emissions, Environ. Sci. Technol., 35, 4198-4204, 2001.

Kolb, C. E., Herndon, S. C., McManus, J. B., Shorter, J. H., Zahniser, M. S., Nelson, D. D., Jayne, J. T., Canagaratna, M. R., and Worsnop, D. R.: Mobile Laboratory with Rapid Response Instruments for Real-time Measurements of Urban and Regional Trace Gas and Particulate Distributions and Emission Source Characteristics, Environ. Sci. Technol., 38, 5694-5703, 2004.

Li, S. M., Anlauf, K. G., Wiebe, H. A., Bottenheim, J. W., Shepson, P. B., and Biesenthal, T.: Emission ratios and photochemical production efficiencies of nitrogen oxides, ketones, and aldehydes in the Lower Fraser Valley during the summer Pacific 1993 oxidant study, Atmos. Environ., 31, 2037-2048, 1997.

Molina, L. T. and Molina, M. J.: Air Quality in the Mexico Megacity, Kluwer Academia Publishers, Netherlands, 2002.

Müller, K.: Determination of aldehydes and ketones in the atmosphere. A comparative long-time study at an urban and a rural site in Eastern Germany, Chemosphere, 35, 2096-2106, 1997.

Platt, U.: in: Monitoring by Spectroscopic Techniques, Differential Optical Absorption Spectroscopy (DOAS) edited by: Sigrist, M. W., Wiley \& Sons, New York, chap. 2, 1994.

Possanzini, M., Di Palo, V., and Cecinato, A.: Sources and photodecomposition of formaldehyde and acetaldehyde in Rome ambient air, Atmos. Environ., 36, 3195-3201, 2002.

Reyes, F., Grutter, M., Jazcilevich, A., González-Oropeza, R.: Analysis of non-regulated vehicular emissions by extractive FTIR spectrometry: tests on a hybrid car in Mexico City, Atmos. Chem. Phys. Discuss., 6, 5773-5796, 2006, http://www.atmos-chem-phys-discuss.net/6/5773/2006/.

Rothman, L. S., Barbe, A., Benner, D. C., Brown, L. R., et al: The HITRAN molecular spectroscopic database: Edition of 2000 including updates through 2001, Journal of Quantitative Spectroscopy and Radiative Transfer, 82(1-4), 5-44, 2003.

Sander, S. P., Friedl, R. R., Ravishankara, A. R., Golden, D. M., Kolb, C. E., Kurylo, M. J., Huke, R. E., Orkin, V. L., Molina, M. J., Moortgat, G. K., and Finlayson-Pitts, B.: Chemical Kinetics and Photochemical Data for Use in Atmospheric Studies, JPL Publication 02-25, Evaluation Number 14, http://jpldataeval.jpl. nasa.gov/, 2002.
Satsumabayashi, H., Kurita, H., Chang, Y.-S., Carmichael, G. R., and Ueda, H..: Photochemical formations of lower aldehydes and lower 15 fatty acids under long-range transport in central Japan, Atmos. Environ., 29, 255-266, 1995.

Secretaria del Medio Ambiente, S. M. A.: Inventario de Emisiones. Mexico DF, http://www.sma.df.gob.mx/sma/modules. php?name=Biblioteca\&dop=getit\&lid=374, 2002 (2002).

Seinfeld, J. H.: Atmospheric Chemistry and Physics of Air Pollution, John Wiley \& Sons Inc., pp. 768, 1986.

Shirley, T. R., Brune W. H., Ren, X., Mao, J., Lesher, R., Cardenas, B., Volkamer, R., Molina, L. T., Molina, M. J., Lamb, B., Velasco, E., Jobson, T., and Alexander, M.: Atmospheric oxidation in the Mexico City Metropolitan Area (MCMA) during April 2003, Atmos. Chem. Phys., 6, 2753-2765, 2006, http://www.atmos-chem-phys.net/6/2753/2006/.

Shorter, J. H., Herndon, S., Zahniser, M. S., Nelson, D. D., Wormhoudt, J., Demerjian, K. L., and Kolb, C. E.: Real-time measurements of nitrogen oxide emissions from in-use New York City transit buses using a chase vehicle Environ. Sci. Technol., 39(20), 7991-8000, 2005.

Vaughn, T. L., Strader, C., Davis, S., and Daling, J. R.: Formaldehyde and cancers of the pharynx, sinus and nasal cavity: I. Occupational exposures, Int. J. Cancer, 38, 677-683, 1986.

Viskari, E. L., Vartiainen, M., and Pasanen, P.: Seasonal and diurnal variation in formaldehyde and acetaldehyde concentrations along a highway in Eastern Finland, Atmos. Environ., 34(6), 917-923, 2000.

Volkamer, R., Molina, L. T., Molina, M. J., Shirley, T., and Brune, W. H.: DOAS measurement of glyoxal as an indicator for fast VOC chemistry in urban air, Geophys. Res. Lett., 32, L08806, doi:10.1029/2005GL022616, 2005b.

Williams, R. L., Lipari, F., and Potter, R. A.: Formaldehyde, methanol and hydrocarbon emissions from methanol-fueled cars, J. Air Waste Manage. Assoc., 40, 747-756, 1990.

Zavala, M., Herndon, S. C., Slott, R. S., Dunlea, E. J., Marr, L. C., Shorter, J. H., Zahniser, M., Knighton, W. B., Rogers, T. M., Kolb, C. E., Molina, L. T., and Molina, M. J.: Characterization of on-road vehicle emissions in the Mexico City Metropolitan Area using a mobile laboratory in chase and fleet average measurement modes during the MCMA-2003 field campaign, Atmos. Chem. Phys. Discuss., 6, 4689-4725, 2006, http://www.atmos-chem-phys-discuss.net/6/4689/2006/.

Zhou, X., Mopper, K., Yin-Nan, Lee, Newman, L., and Xiaohur, Chen: Tropospheric formaldehyde concentration at the Mauna Loa Observatory during the Mauna Loa Observatory Photochemistry Experiment 2, J. Geophys. Res., 101(D9), 14 711-14 719 , 1996. 